\title{
PENERAPAN E-LEARNING UNTUK MENINGKATKAN KETERAMPILAN GURU BK DALAM MEMBERIKAN LAYANAN PENDIDIKAN SEKS TERHADAP SISWA
}

\author{
Dwi Sri Rahayu ${ }^{1}$, Chaterina Yeni Susilaningsih ${ }^{2}$, Chatarina Dian Indrawati ${ }^{3}$ \\ ${ }^{1,2}$ Program Studi Bimbingan dan Konseling, Fakultas Keguruan dan Ilmu Pendidikan \\ ${ }^{3}$ Program Studi Teknik Industri, Fakultas Teknik \\ Universitas Katolik Widya Mandala Madiun \\ Email: dwirahayu.gp@gmail.com
}

\begin{abstract}
A gadget product that seems to be a mandatory equipment for students is a smartphone. Such conditions present positive and negative impacts. The freedom of students to access everything from their smartphone triggers free sex. Students feel awkward and embarrassed to ask questions or just share about their sex lives. So they tend to look for answers by accessing information needed on the internet through their smartphone. This is the driving factor for promiscuity. The aim of this PKM-S is that BK teachers have the skills to provide sex education to their students by utilizing technological sophistication. PKM-S is held at St. Vocational School. Bonaventura 1 Madiun. The method used in the implementation of the PKM-S is socialization, training, and mentoring. The results achieved are 1) students begin to dare to talk about their sex life with counselors, 2) students know the adverse effects of free sex behavior, 3) students are able to filter information about sex, 4) BK teachers provide e-learning based sex education services, 5) enhancing BK service innovation. Partners feel very helpful to provide prevention to St. Vocational School students. Bonaventure 1 Madiun in order to keep away from free sex. Because in the implementation of the PKM-S it produces products in the form of e-material which contains information about sex education, including one of them is the impact caused by free sex.
\end{abstract}

Keywords: e-learning, Sex education, BK teacher

\begin{abstract}
Abstrak.Produk gadget yang seolah menjadi peralatan wajib bagi siswa adalah smartphone. Kondisi demikian menghadirkan dampak positif dan negatif. Kebebasan siswa mengakses semua hal dari smartphonenya memicu terjadinya perilaku seks bebas. Siswa merasa canggung dan malu untuk bertanya atau sekedar sharing tentang kehidupan seks mereka. Sehingga mereka cenderung mencari jawaban dengan mengakses informasi yang dibutuhkan di internet melalui smartphonenya. Hal ini yang menjadi faktor pendorong terjadinya pergaulan bebas. Tujuan PKM-S ini adalah agar Guru BK memiliki keterampilan untuk memberikan pendidikan seks kepada siswanya dengan memanfaatkan kecanggihan teknologi. PKM-S dilaksanakan di SMK St. Bonaventura 1 Madiun. Metode yang digunakan dalam pelaksanaan PKM-S ini adalah sosialisasi, pelatihan, dan pendampingan. Hasil yang dicapai adalah 1) siswa mulai berani untuk membicarakan kehidupan seksnya dengan guru BK, 2) siswa mengetahui dampak buruk dari perilaku seks bebas, 3) siswa mampu memfilter informasi tentang seks, 4) Guru BK memberikan layanan pendidikan seks berbasis e-learning, 5) peningkatan inovasi layanan BK. Mitra merasa sangat terbantu untuk memberikan pencegahan kepada siswa SMK St. Bonaventura 1 Madiun agar bisa menjauhkan diri dari perilaku seks bebas. Karena di dalam pelaksanaan PKM-S ini menghasilkan produk berupa e-material yang memuat informasi seputar pendidikan seks, termasuk salah satunya adalah dampak yang diakibatkan oleh perilaku seks bebas.
\end{abstract}

Kata kunci: e-learning, Pendidikan Seks, Guru BK

\section{PENDAHULUAN}

Di zaman yang serba modern ini tidak sulit rasanya untuk melihat atau menemukan siswa SMK yang tengah asyik dengan gadgetnya, salah satu produk gadget yang seolah-olah menjadi peralatan yang wajib dimiliki siswa adalah smartphone. Bukan hanya siswa SMK, akan tetapi mulai dari anak-anak hingga orang dewasa hampir semuanya memiliki smartphone. Bahkan ada individu yang memiliki smartphone lebih dari satu unit. Tercatat di Badan Pusat
Statistik Nasional pada tahun 2016 penduduk Indonesia memiliki handphone mencapai $58,30 \%$. Kondisi ini menunjukan kenaikan selama dua tahun terakhir, pada tahun 2014 kepemilikian HP mencapai 51,49\% dan pada tahun 2015 mencapai 56,92\%. Kondisi demikian bagaikan dua bilah mata pedang. Selalu menghadirkan dampak positif dan negatif terhadap penggunanya. 
Dampak positif yang diakibatkan dengan pemanfaatan smartphone adalah siswa mudah menemukan informasi yang dibutuhkan dalam pembelajaran. Mereka juga dengan mudah mengakses materi-materi yang berkaitan dengan mata pelajaran di sekolah. Rasa ingin tahu remaja yang tinggi perihal seks cenderung berdampak pada hal negatif dalam penggunaan smartphone, misalnya adalah membuka situs-situs yang terdapat konten pornografi.

Perilaku nyata yang terjadi akibat pergaulan bebas di kalangan remaja semakin memprihatinkan. Seperti yang tercatat di detiknews pada hari Kamis, 09 Maret 2017, terdapat pelajar di Surabaya yang mesum di kamar pas. Bahkan ada pula pelajar di Bekasi yang secara patungan menyewa kamar-kamar kos untuk kemudian dipergunakan berbuat mesum.

Hasil serupa yang menunjukan perilaku seks bebas di kalangan pelajar adalah dari survey yang melibatkan 4.500 responden, ternyata $62,7 \%$ siswa SMP mengaku sudah pernah berhubungan intim layaknya suami istri. Menurut Dokter dari BKOW Gorontalo, Sulianti Otto, mengungkakan penyebab remaja usia SMP saat ini bertindak di luar kepatutan karena mereka pernah dan aktif menonton materi pornografi. Hal ini dikuatkan dengan hasil survei yang dilakukan BKKBN pada akhir 2015 menyatakan, 73\% remaja di beberapa kota besar di Indonesia melakukan seks pranikah (Jurnal asia, 2015). Mudahnya pelajar mengakses konten pornografi menjadi pemicu semakin maraknya perilaku seks bebas. Kalangan remaja kerap menggunakan smartphone untuk mencari pasangan dan di antara mereka cenderung mudah terlibat dalam pergaulan bebas (Kompas, 2012).

Bebasnya pelajar mengakses "segalanya" dari smartphone inilah yang perlu menjadi perhatian para orang tua, pemerintah dan sekolah. Bimbingan dan konseling memiliki andil yang cukup luas dalam hal ini. Konselor sekolah memiliki peran yang strategis untuk mengatasi maraknya perilaku seks bebas di kalangan pelajar. Dengan memanfaatkan kondisi yang serba digital ini, pemberian layanan bimbingan dan konseling tidak harus melalui tatap muka, ceramah, dan konvensional. Konselor dapat melakukan kegiatan layanan bimbingan dan konseling dengan daring. Tidak menutup kemungkinan pelaksanaan layanan pendidikan seks untuk siswa juga melalui sistem daring pula.

Menurut Geldard (2012) pendidikan seks meliputi bagaimana membuat orang tua siswa memiliki keterampilan komunikasi tentang seksualitas secara tepat dengan anaknya, informasi kontrasepsi, pencegahan kehamilan, serta perawatan kesehatan reproduksi. Dalam hal ini guru BK dapat memberikan materi yang cukup luas dan sesuai dengan tahap perkembangan siswanya.

Sedangkan menurut Sarwono (2005) pendidikan seks adalah salah satu cara untuk mengurangi atau mencegah penyalahgunaan seks, khususnya untuk mencegah dampak negatif, seperti kehamilan yang tidak direncanakan, penyakit menular seksual, depresi dan perasaan berdosa. Di dalam pendidikan seks ini bukan hanya perihal seks saja yang dapat dijelaskan. Lebih luas lagi adalah bagimana nilai-nilai bisa ditransformasikan dari pendidik ke pada siswa. Materi tentang seks tidak disampaikan secara vulgar akan tetapi diberikan secara kontekstual. Pendidik memperhatikan norma-norma yang berlaku dalam masyarakat, sehingga apa yang boleh dan tidak boleh dilakukan dan bagaimana cara melakukannya tanpa melanggar aturan yang berlaku menjadi bagian yang tidak terpisahkan dalam pelaksanaan pendidikan seks.

Pendidikan seks sangat diperlukan dalam upaya menangani perilaku seks bebas di kalangan pelajar. Dengan adanya pendidikan seks, siswa akan mengetahui dan memahami bahaya-bahaya yang mengiringi perilaku tersebut. Diharapkan apabila mereka mengetahui dan memahami apa saja yang akan mereka hadapi apabila melakukan seks bebas, para remaja akan lebih berhati-hati memutuskan tindakan yang dilakukan. Menjauhi segala aktivitas yang menuju pada pergaulan bebas. Hal ini sesuai dengan pendapat Nadeak (1991) bahwa jika pendidikan seks tidak disampaikan maka anak tidak akan memahami fungsi seks dalam tubuh mereka. Bahayanya adalah ketika mereka mencari tahu dari sumber yang tidak tepat, dan keterangan yang mereka 
peroleh menyesatkan, maka dimungkinkan akan berdampak kurang sehat bagi dirinya.

Oleh karena itu dalam kesempatan ini, tim pengusul kegiatan dari Program Studi Bimbingan dan Konseling memberikan intervensi dalam rangka memenuhi kebutuhan akan tugas pekembangan remaja dalam aspek pengetahuan pendidikan seks. Melalui sebuah program kegiatan pendampingan kepada guru BK di sekolah untuk memberikan layanan pendidikan seks dengan sistem daring berbantuan e-learning. Hal ini dimaksudkan agar para siswa mendapatkan jawaban yang benar dan dari sumber yang dapat dipertanggungjawabkan dengan lebih leluasa melalui smartphone mereka masing-masing. Bentuk pendidikan seks melalui e-learning yang dimaksudkan akan memasukan materi-materi yang berkaitan dengan definisi seks, kesehatan reproduksi, aborsi, dan penyakit menular seksual sebagai akibat dari perilaku seks bebas.

Tujuan kegiatan PKM-S ini adalah agar Guru BK memiliki keterampilan untuk memberikan pendidikan seks kepada siswanya dengan memanfaatkan kecanggihan teknologi yang ada, yakni dalam bentuk program pemberian layanan pendidikan seks berbantuan pembelajaran online atau e-learning. Dengan inovasi ini, siswa yang memiliki rasa enggan untuk bertanya atau sharing pengalaman hidupnya terkait dengan seks secara tatap muka, maka bisa memanfaatkan cyber guidance sebagai hasil dari kegiatan PKM-S ini.

Target dan luaran yang dihasilkan dari pengabdian masyarakat ini adalah sebagai berikut:

a. Peningkatan pengetahuan mitra terkait dengan urgensi e-learning. Pemahaman mitra terkait dengan hal ini bisa diukur melalui kuesioner kebutuhan dan kebermanfaatan e-learning dalam layanan BK, yang dikembangkan oleh tim pengusul.

b. Tersusun e-material untuk bahan pelaksanaan pendidikan seks berbasis e-learning. Produk $e$ material berjumlah 6 produk yang terdiri dari 2 PPT, 2 PDF, dan 2 Film Pendek yang berkaitan dengan pendidikan seks.

c. Peningkatan keterampilan guru BK dalam memberikan layanan bimbingan dan konseling di sekolah, khususnya tentang pendidikan seks.
Peningkatan keterampilan guru BK dalam memberikan layanan pendidikan seks diukur dengan pre tes dan pos tes.

d. Artikel ilmiah yang dimuat di jurnal Pengabdian Terapan Abdimas Universitas PGRI Madiun.

e. Artikel yang dimuat dalam prosiding seminar nasional hasil pengabdian kepada masyarakat.

f. Artikel yang di muat dalam surat kabar harian Radar Madiun.

g. Menghasilkan video kegiatan sebagai dokumentasi pelaksanaan yang di unggah di laman wimatvchannel.

h. Peningkatan pengetahuan siswa terhadap seks, sehingga siswa tidak mencari jawaban dari rasa penasaran ke sumber yang tidak tepat. Hal ini meminimalisir terjadinya perilaku seks bebas karena kesalahan informasi yang didapatkan siswa. Peningkatan pengetahuan siswa terhadap seks diukur dengan kuesioner pre tes dan post tes.

\section{METODE PELAKSANAAN}

Agar tujuan PKM-S ini terlaksana, diperlukan metode yang tepat. Metode tersebut dilaksanakan dengan langkah-langkah sebagai berikut:

1. Melakukan sosialisasi tentang gambaran umum kegiatan pengabdian kepada masyarakat ini dilakukan kepada kepala sekolah dan guru BK.

Tim pengusul memberikan sosialisasi tentang apa itu e-learning, e-material, dan bagaimana hubungan antar keduanya serta bagaimana pemanfaatan e-leraning ini dalam layanan $\mathrm{BK}$ khususnya untuk pendidikan seks terhadap siswa.

2. Berkoordinasi dengan pihak SMK St. Bonaventura I Madiun (khususnya Guru BK) berkaitan dengan kegiatan pendampingan. Terutama hal-hal yang berhubungan dengan tempat, sarana prasarana yang diperlukan untuk kegiatan pelatihan, serta jadwal pelaksanaan. Peserta pelatihan adalah seluruh Guru BK dan operator sekolah. Adapun subjek atau target sasaran dalam kegiatan pendampingan ini adalah seluruh siswa di SMK St. Bonaventura 1 Madiun sejumlah 75 siswa. Pelatihan dijadwalkan sebanyak empat kali pertemuan, dengan durasi setiap pertemuan selama 1 jam.

3. Menyebar angket pre tes kepada seluruh subjek atau sasaran pengabdian kepada masyarakat, sejumlah 75 siswa.

4. Pelaksanaan pendampingan untuk membuat $e$ material dengan tema yang berbeda-beda, antara lain: (1) Arti dan pentingnya pendidikan seks, (2) 
Say No to Free Sex, (3) Aborsi dan penyakit menular seks sebagai dampak seks bebas dan (4) Kesehatan reproduksi. Secara rinci rencana pelaksanaan kegiatan diuraikan dalam tabel 1.
5. Menyebar angket post tes untuk seluruh siswa di SMK St. Bonaventura 1 Madiun, sejumlah 75 siswa.

Tabel 1. Sebaran Tema Abdimas

\begin{tabular}{|c|c|c|c|c|c|}
\hline No & Tema & Waktu & $\begin{array}{l}\text { Produk } \\
\text { e-material }\end{array}$ & Lokasi & Peserta \\
\hline 1 & $\begin{array}{l}\text { Arti dan pentingnya } \\
\text { pendidikan seks }\end{array}$ & $\begin{array}{l}\text { Pertemuan } \\
\text { Ke } 1\end{array}$ & PPT & $\begin{array}{l}\text { SMK St. Bonaventura } 1 \\
\text { Madiun }\end{array}$ & $\begin{array}{l}\text { Guru } \quad \text { BK } \& \\
\text { Operator sekolah }\end{array}$ \\
\hline 2 & $\begin{array}{l}\text { Aborsi dan penyakit } \\
\text { menular seks sebagai } \\
\text { dampak seks bebas }\end{array}$ & $\begin{array}{l}\text { Pertemuan } \\
\text { Ke } 2\end{array}$ & Film pendek & $\begin{array}{l}\text { SMK St. Bonaventura } 1 \\
\text { Madiun }\end{array}$ & $\begin{array}{l}\text { Guru } \quad \text { BK } \& \\
\text { Operator sekolah }\end{array}$ \\
\hline$\overline{3}$ & Say No to Free Sex & $\begin{array}{l}\text { Pertemuan } \\
\text { Ke } 3\end{array}$ & PDF & $\begin{array}{l}\text { SMK St. Bonaventura } 1 \\
\text { Madiun }\end{array}$ & $\begin{array}{lc}\text { Guru } & \text { BK } \\
\text { Operator sekolah } & \end{array}$ \\
\hline$\overline{4}$ & Kesehatan reproduksi & $\begin{array}{l}\text { Pertemuan } \\
\text { Ke } 4\end{array}$ & PPT & $\begin{array}{l}\text { SMK St. Bonaventura } 1 \\
\text { Madiun }\end{array}$ & $\begin{array}{lr}\text { Siswa SMK } & \text { St. } \\
\text { Bonaventura } & 1 \\
\text { Madiun } & \\
\end{array}$ \\
\hline
\end{tabular}

\section{HASIL DAN PEMBAHASAN}

Kegiatan Program Kemitraan Masyarakat Stimulus (PKM-S) telah dilaksanakan melalui 3 tahap yaitu sosialisai, pelatihan dan pendampingan. Pelaksanaan kegiatan PKM-S ini dapat dijelaskan sebagai berikut:

\section{A. Sosialisasi}

Pada tahap ini, tim pengusul memberikan informasi secara komprehensif tentang pentingnya pelaksanaan layanan pendidikan seks dengan metode berbasis e-learning. Keterampilan guru BK dalam mengolah materi dengan format e-material sangat diperlukan dalam mendukung keberlaksanaan kegiatan PKM-S ini. Dalam kegiatan ini pula pemahaman guru BK dalam memanfaatkan kekuatan dunia maya untuk mensinergikan pemenuhan kebutuhan informasi siswa terkait dengan pendidikan seks perlu diberikan. Kegiatan ini bermanfaat untuk menanamkan pondasi paradigma yang sama antara tim pengusul dan mitra. Sosialisasi dilaksanakan pada hari Senin, 1 April 2019 dengan menghasilkan satu konsep bahwa penting adanya inovasi dalam memberikan layanan bimbingan dan konseling, khususnya tentang pendidikan seks. Mengingat siswa merupakan generasi digital maka di era revolusi industri 4.0 ini, guru BK harus adaptif terhadap kemajuan teknologi. Dengan melaksanakan layanan dengan basis e-learning sangat membantu mitra dalam menjawab kebutuhan siswa saat ini.
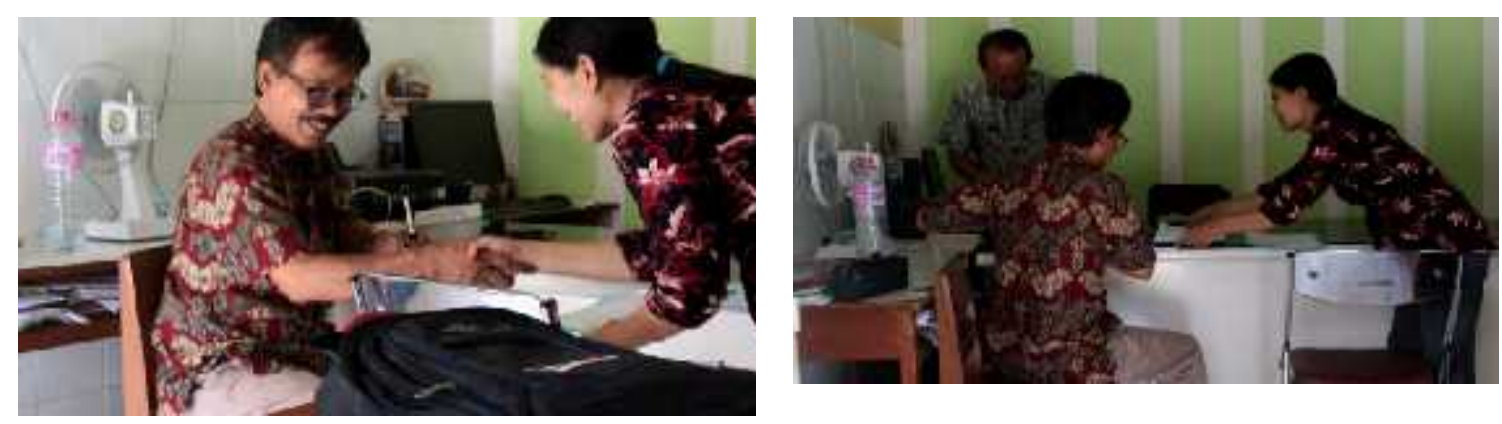

Gambar 1. Sosialisasi Kegiatan PKM-S kepada Mitra

\section{B. Pelatihan}

Berdasarkan kegiatan sosialisasi dan koordinasi awal, diketahui bahwa permasalahan yang tengah dihadapi mitra PKM-S perlu ada solusi dengan memanfaatkan kecanggihan teknologi saat ini. Mitra belum pernah melakukan layanan Bimbingan dan Konseling dengan memanfaatkan fasilitas internet yang disediakan sekolah. Meskipun pihak sekolah memiliki fasilitas internet yang baik dan operator sekolah yang ahli di bidangnya akan tetapi belum pernah dilaksanakan program e-learning dalam proses pembelajaran, terlebih proses pemberian layanan Bimbingan dan Konseling. Sedangkan kondisi saat ini 
sangat memungkinkan apabila layanan diberikan sesuai dengan kemajuan IPTEK.

Keterampilan memberikan layanan dengan basis e-learning perlu dimiliki oleh setiap pendidik. Sehingga perlu tenaga pendidik bisa diberikan pelatihan berkenaan dengan hal tersebut. Guru BK bisa memanfaatkan jaringan internet yang tersedia di sekolah untuk semakin memperkaya pemahaman siswa terkait dengan pendidikan seks. Dengan konten e-material yang menarik dan bisa diakses kapanpun melaui gawai, siswa akan termotivasi untuk memenuhi rasa ingin tahunya mengenai pendidikan seks ke website yang tepat, yakni situs pembelajaran online yang berbentuk kelas atau layanan online oleh Guru BK.

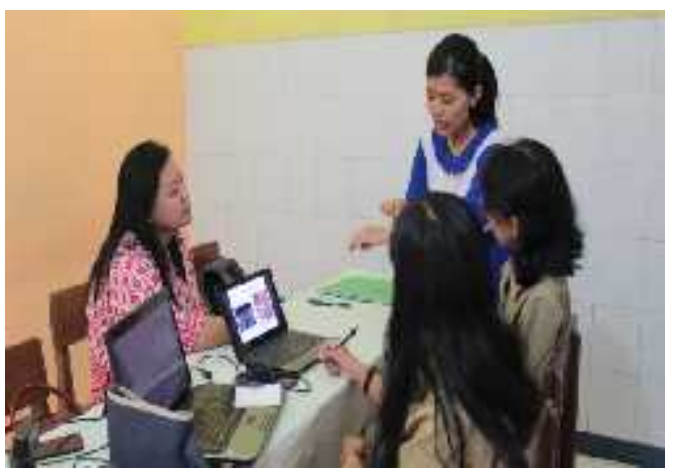

Gambar 2. Pelatihan Membuat E-material PPT tentang Pendidikan Seks

Informasi lain yang dibahas dengan mitra adalah bagaimana proses pembuatan PPT yang efektif untuk dijadikan sebagai e-material dalam program e-learning. Dengan memanfaatkan PPT tersebut, diharapkan siswa tidak akan semakin bingung dengan materi yang disampaikan oleh guru BK di website. Sehingga tujuan e-learning untuk menjawab kebutuhan siswa ketika mereka malu bertanya pada orang tua atau guru tentang seluk beluk seks bisa tercapai.

Pelatihan tahap dua, mitra dibekali dengan keterampilan untuk membuat e-material

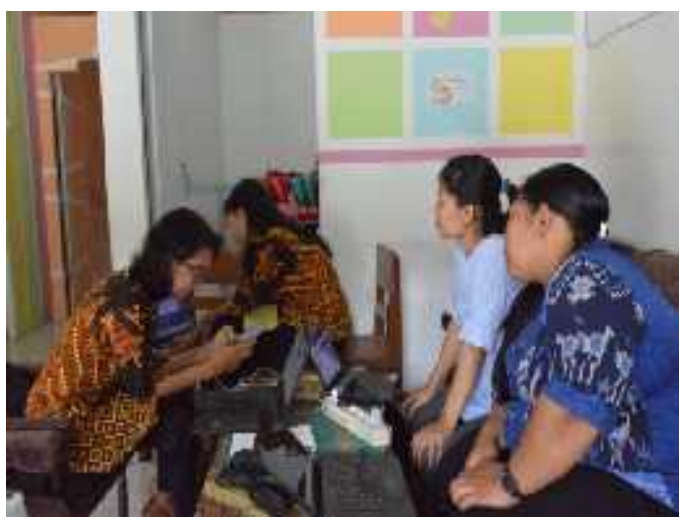

Kegiatan pelatihan PKM-S ini diberikan pada guru BK dan operator sekolah. Hari pertama dilaksanakan tanggal 4 April 2019 diisi dengan pembuatan e-material PPT yang dimulai dari jam 08.00 - 12.30. Diawali dengan penjelasan tentang pendidikan seks meliputi definisi, ruang lingkup, pentingnya pendidikan seks, bentuk-bentuk pendidikan seks untuk remaja, dan metode pendidikan seks kepada remaja. Pemahaman tentang pendidikan seks perlu diberikan agar mitra memiliki pemahaman tidak seperti orang pada umumnya, bahwa hal-hal yang berkaitan dengan seks hanya membicarakan tentang hubungan seks.

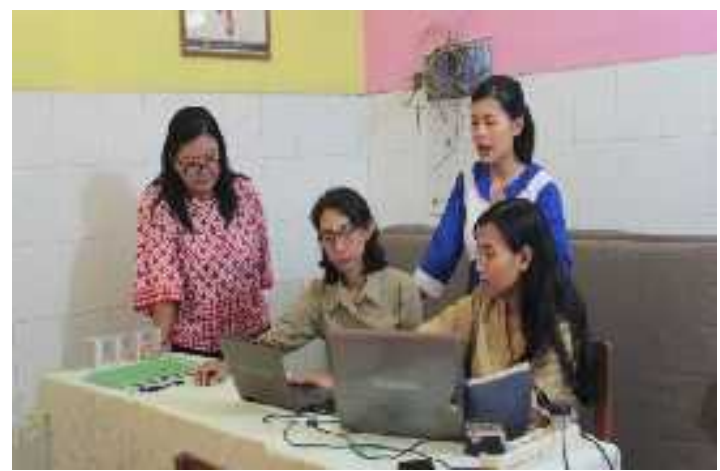

dalam bentuk PDF. Pelaksanaan pelatihan ke dua ini berlangsung pada tanggal 5 April 2019 jam 08.00-12.00. Mitra mendapatkan pengetahuan bagaimana menyusun materi tentang pendidikan seks yang menarik dengan tampilan PDF yang sewaktu-waktu bisa dipelajari dan diunduh oleh siswa. PDF memiliki keunggulan lebih ringan daripada file microsoft word sehingga memudahkan dalam upload file ke akun $e$ learning.

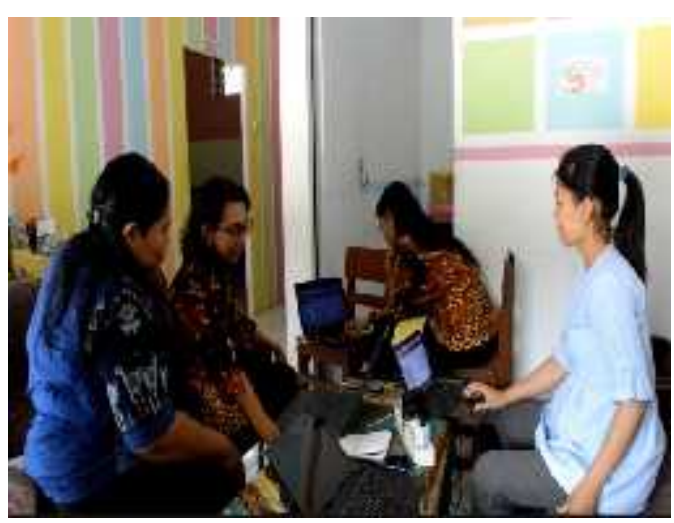




\section{Gambar 3. Pelatihan Pembuatan E-material dalam Bentuk PDF tentang Pendidikan}

Seks

Tahap selanjutnya adalah pelatihan menghasilkan film pendek yang bertema pembuatan film pendek. Film pendek merupakan sarana yang cukup efektif untuk menyampaikan sebuah pesan kepada penonton. Terlebih di era digital ini, kaum muda cenderung memiliki minat baca yang menurun. Mereka lebih memilih menonton video daripada harus membaca informasi tertentu. Sehingga dalam kegiatan PKM-S ini, mitra juga dilatih bagaimana membuat film pendek yang memiliki pesan atau makna agar siswa tidak terjerumus dalam kegiatan free sex. Dari pelatihan ini

bagaimana dampak free sex terhadap kehidupan remaja. Dampak yang ditampilkan dalam film pendek ini adalah dampak negatif aborsi. Mitra dilatih bagaimana membuat skenario untuk film yang hanya berdurasi 2 sampai 9 menit. Dengan durasi maksimal 9 menit tersebut film ini harus membuat penonton mendapatkan makna tidak ada yang bisa dibanggakan dari free sex. Bahkan lebih parah adalah nyawa bisa melayang karena aborsi.
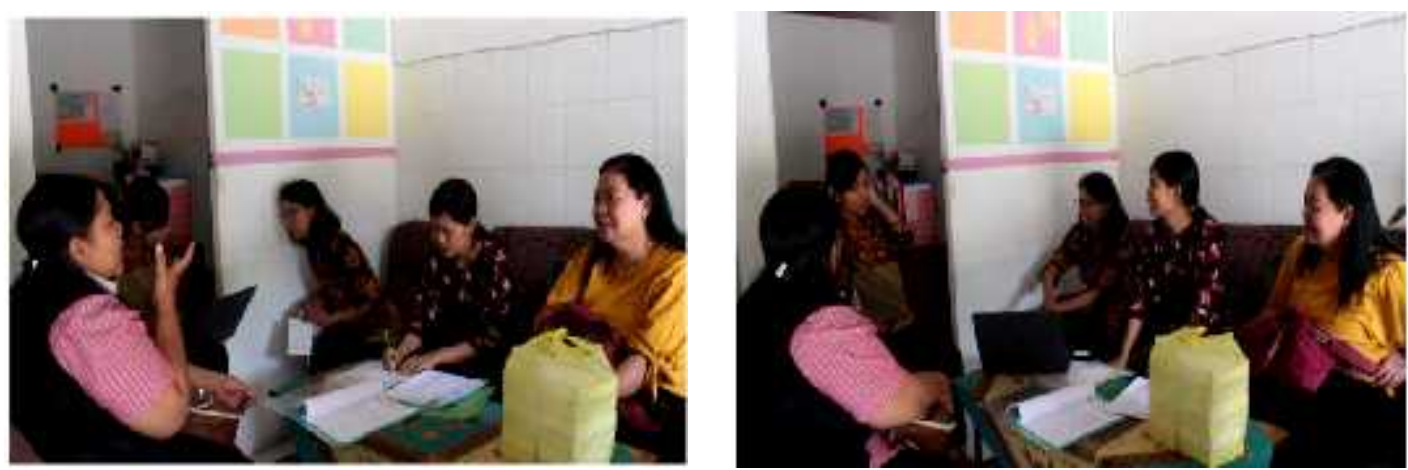

Gambar 4. Pelatihan Pembuatan E-Material dalam Bentuk Film Pendek tentang Pendidikan Seks

Pelatihan tahap ke empat adalah

keterampilan mengupload, menginvetaris, dan bagaimana mengelola e-material dalam website guru BK agar siswa mudah untuk mengakses dan memahami materi. Kegiatan ini dilaksanakan pada tanggal 6 April 2019. Mitra mendapatkan
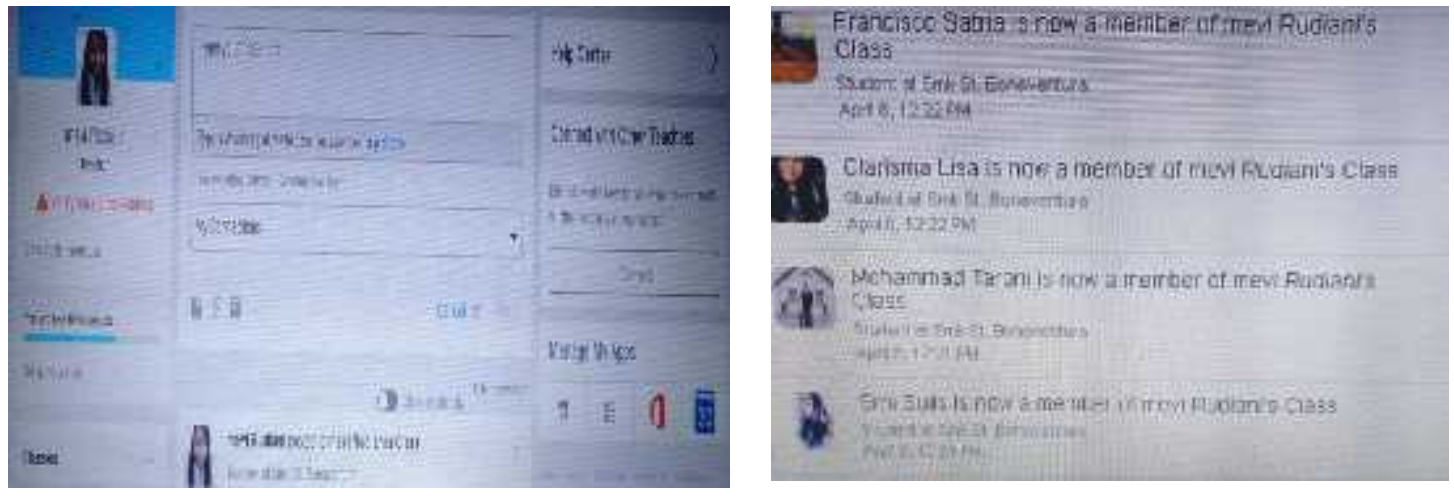

Gambar 5. Tampilan akun Guru BK dan Daftar Siswa yang Mengikuti Kelas E-Learning Guru BK

\section{Pendampingan}

Produk e-material yang telah dihasilkan oleh mitra baik yang berupa PPT, PDF, maupun film pendek dari tahap pelatihan pada muaranya diupload di akun mitra. Selanjutnya kegiatan pendampingan dilaksanakan pada tanggal 8 April

2019 jam 10.00-13.20. Pendampingan berisi kegiatan tim pengusul bersama dengan mitra mensosialisasikan e-learning tentang pendidikan seks ke seluruh siswa SMK St. Bonaventura 1 Madiun sejumlah 75 siswa. 

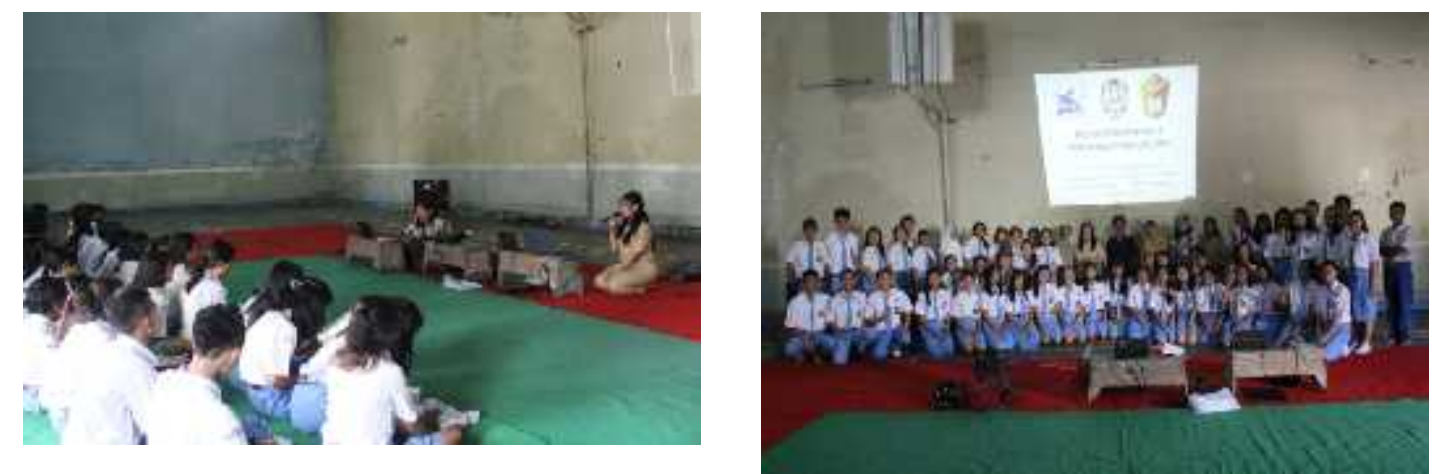

Gambar 6. Pendampingan kepada Siswa SMK St. Bonaventura 1 Madiun

Dalam sesi pendampingan ini, mitra juga diajari bagaimana memberikan komentar menjadi narasumber untuk seluruh siswanya. Menginformasikan apa itu e-learning, apa itu pendidikan seks, dan bagaimana mengakses seluruh materi yang ada di kelas/classes Guru BK dalam e-learning. Diawali dengan pembuatan akun untuk register lalu dilanjutkan dengan login menjadi siswa/student agar bisa membaca atau mengunduh materi di akun Guru BK. Lalu siswa terhadap materi pendidikan seks. Komentar dapat berupa pertanyaan, sharing opini, atau sanggahan. Guru BK juga memiliki ruang untuk memberikan feed back dari komentar siswa. Sehingga meskipun tidak bertatap muka, disediakan wadah untuk diskusi agar siswa lebih memahami materi.
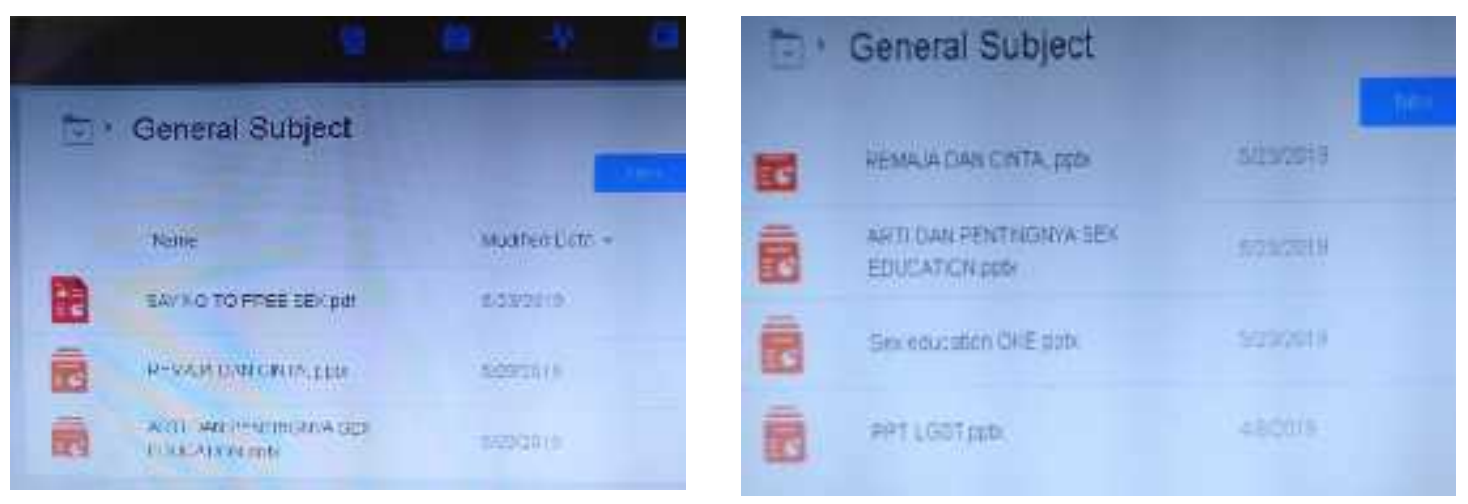

Gambar 7. Tampilan File E-material Guru BK 


\section{SIMPULAN DAN SARAN}

Kehidupan remaja yang sangat rentan dengan pengaruh dunia maya harus menjadi perhatian lebih para pendidik khususnya Guru BK. Pemanfaatan kecanggihan teknologi untuk pemberian layanan informasi terkait dengan pendidikan seks sangat mungin untuk dilaksanakan. Melalui pembelajaran online atau e-learning mitra menyadari bisa mempermudah Guru BK untuk menjalin komunikasi pembelajaran dengan siswa tanpa harus tatap muka. Sehingga siswa yang merasa canggung untuk bertanya kepada Guru BK tentang kehidupan seks nya bisa mengakses informasi tersebut dalam e-learning.

Melalui program PKMS ini, maka mitra merasa sangat terbantu untuk memberikan pencegahan kepada siswa SMK St. Bonaventura 1 Madiun agar bisa menjauhkan diri dari perilaku seks bebas. Karena di dalam pelaksanaan PKMS ini menghasilkan produk berupa e-material yang memuat informasi seputar pendidikan seks, termasuk salah satunya adalah dampak yang diakibatkan oleh perilaku seks bebas. Dengan mengetahui dampak negatif perilaku seks bebas, diharapkan siswa tidak akan melakukan kegiatan atau hal-hal yang mengarah pada perilaku seks bebas.

Kegiatan PKM-S sangat diharapkan oleh mitra karena dapat menambah pengetahuan, keterampilan serta inovasi layanan bagi siswanya. Sehingga mitra berharap akan ada kegiatan serupa untuk lebih memperkaya metode pemberian layanan bimbingan dan konseling pada khususnya dan tentunya untuk mata pelajaran lain jika dimungkinkan.

\section{UCAPAN TERIMAKASIH}

Ucapan terima kasih kepada 1) Universitas Katolik Widya Mandala Madiun yang memberi peluang pengusul untuk mengajukan PKM-S ini, 2) Direktorat Riset dan Pengabdian Masyarakat Direktorat Jendral Penguatan Riset dan Pengembangan Kementerian Riset, Teknologi dan Pendidikan Tinggi, Republik Indonesia yang telah mendanai PKM-S ini, 3) SMK St. Bonaventura 1 Madiun yang bersedia menjadi mitra PKM-S ini.

\section{DAFTAR PUSTAKA}

Geldard, Kathryn. 2010. Konseling Remaja (Intervensi Praktis bagi Remaja Beresiko). Yogyakarta : Pustaka Pelajar.

https://lifestyle.kompas.com/read/2012/10/31/151 14598/Smartphone.Picu.Pergaulan.Bebas .Remaja, Diakses tanggal 6 Juli 2018.

https://www.bps.go.id/linkTableDinamis/view/id/ 985. Diakses tanggal 6 Juli 2018.

https://www.jpnn.com/news/miris-62-persenanak-smp-pernah-berhubungan-intim-21persen-pernah-aborsi. Diakses tanggal 6 Juli 2018.

Nadeak, Wilso. 1991. Memahami Anak Remaja. Yogyakarta: Kanisius.

Sarwono, Sarlito Wirawan. 2005. Psikologi Remaja. Jakarta: Rajawali Pers.

Sitorus, $\quad$ Satriana. 2016. http://www.jurnalasia.com/opini/pengaru h-gadget-di-kalangan-pelajar. Diakses tanggal 7 Juli 2018.

Wahyudiyanta, Imam. 2017.

https://news.detik.com/berita-jawatimur/d-3443057/kasus-remaja-mesumdi-kamar-pas-di-mata-komnasperlindungan-anak. Diakses tanggal 6 Juli 2018. 